\title{
APPLICATION OF FLUX-CORED WIRES FOR WELDING IN INDUSTRY
}

\author{
R. ROSERT \\ ITW Welding GmbH \\ 67317, Altleiningen, Germany. E-mail: reinhard.rosert@gmx.de
}

\begin{abstract}
Mechanized and automated processes of flux-cored wire arc welding and surfacing are ever wider applied in many countries in manufacture and repair of various products and structures in many industries and productions. Some advantages of flux-cored wire MAG process are considered, compared to solid wire MMA and MAG processes. One of effective applications of flux-cored wires, in particular, is main pipeline construction. Types of welding systems developed in a number of countries for making position butt joints of pipelines are given. 3 Tables, 12 Figures.
\end{abstract}

Keywords: mechanized arc welding, flux-cored wire, application advantages, welding (surfacing) efficiency, automated welding systems, mechanical properties

Welding belongs to the most widely spread processes applied in industry for fabrication of metal structures. This accounts for development of numerous welding processes and filler materials. The main objectives of these developments are development of welding consumables for welding various steel types, and development of new and high-efficient welding processes.

Tendencies in development of welding processes are evolving towards mechanization and automation. The graph (Figure 1) shows how individual welding processes are distributed by various regions of the world. In the USA, Japan and EU mainly mechanized and automated welding processes are used. Application of stick electrodes is relatively small.

In China and many Asian countries more than $50 \%$ of all welding consumables are stick electrodes. Level of mechanization is lower, respectively thus lowering welding process efficiency. Application of manual arc welding with stick electrodes in these countries is preferable, as the cost of welding equipment and auxiliary materials is relatively low.

An alternative to application of stick welding electrodes are flux-cored wires. Flux-cored wire is an endless electrode in the form of wire, filled with the following components for diverse applications: slag- and gas-forming, arcing stabilizers, alloying powders, ferromaterials and microalloying elements.

There exist two main kinds of flux-cored wire: seamless (Figure 2, $a$ ) and rolled (Figure 2, b).

(c) R. ROSERT, 2014
Depending on purpose, basic and rutile fluxcored wires are used, both slag-containing and metal-powder ones. Figure 3 shows flux-cored wire classification by various criteria. Application of flux-cored wires offers the following advantages:

- performance of high-quality welds by less skilled welders;

- shorter time to train welders in technique in different spatial positions;

- reducing the risk of lack-of-penetration at torch deviation from the correct trajectory, as the weld column is very wide;

- minimizing sensitivity of penetration and weld quality to unforeseen change of welding mode settings;

- lowering defect repair costs.

At present flux-cored wires are becoming ever wider accepted in different productions such as shipbuilding, bridge, pipe and turbine construction, drilling platforms, car industry, steel structures, vessel and apparatus building, chemical engineering, rail vehicles, casting and metallur-

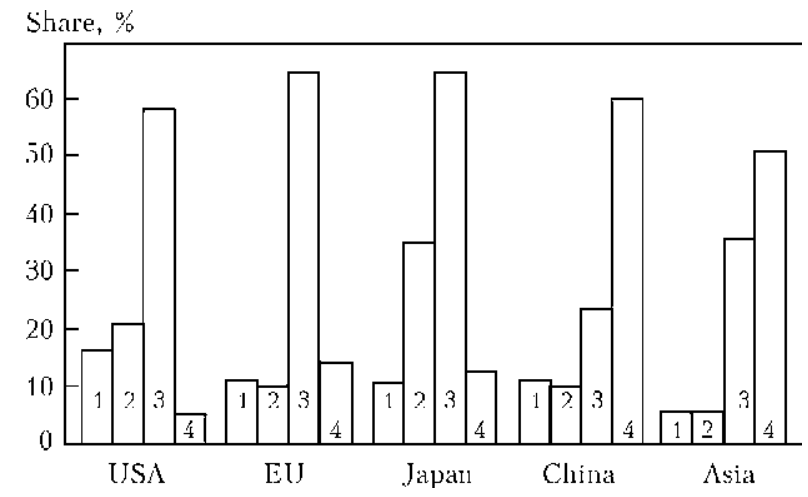

Figure 1. Structure of welding process application in world fabrication, as it was in 2010: 1 - submerged-arc; 2 gas-shielded flux-cored wire; 3 - gas-shielded solid wire; 4 - stick electrode welding 

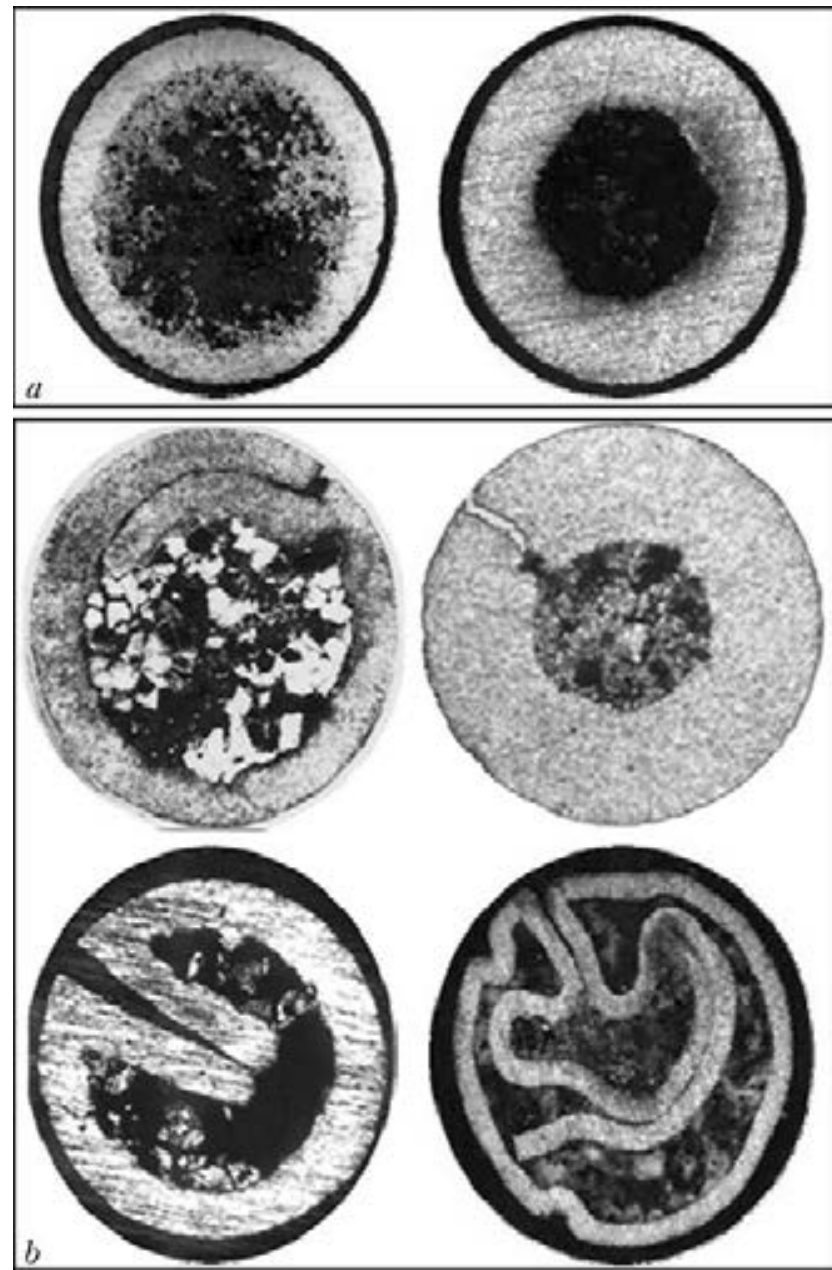

Figure 2. Seamless $(a)$ and rolled $(b)$ flux-cored wires

gical industry, mobile cranes, machines for road construction and repair.

Efficiency of flux-cored wire welding is directly related to welding current and reaches high values (Figure 4).

In industry mostly rutile flux-cored wires with rapidly-solidified slag are used, which allow outof-position welding by high currents. Deposited metal composition provides the required me-

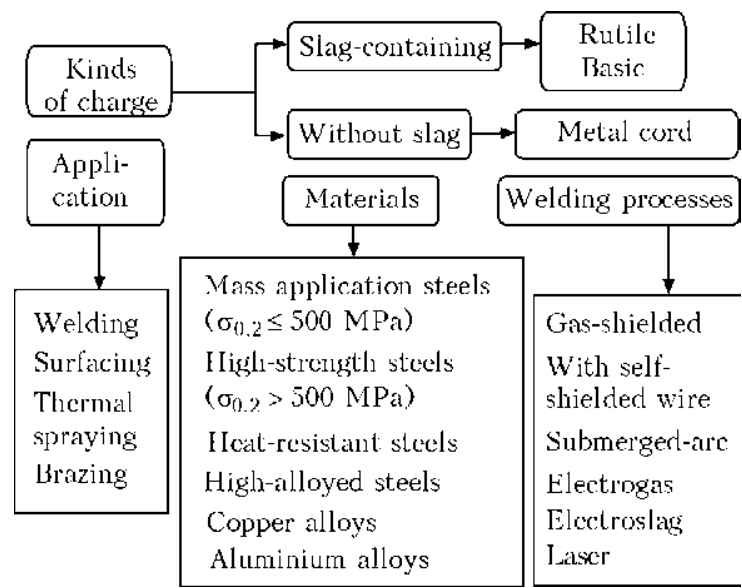

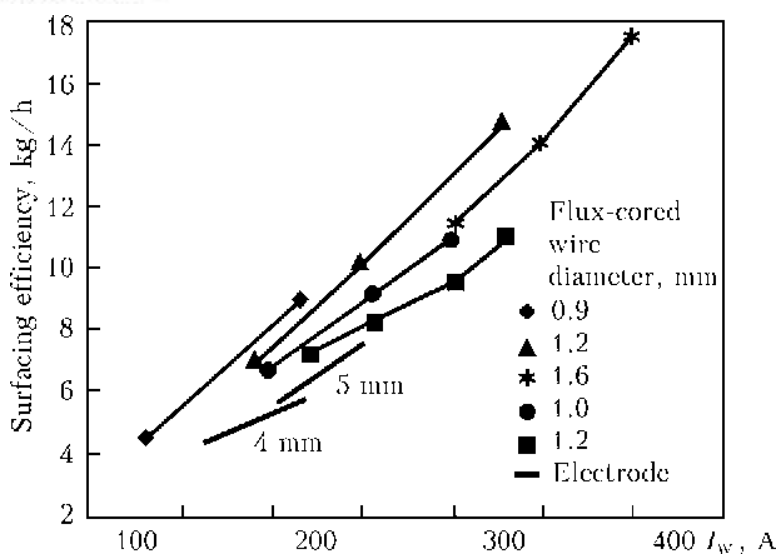

Figure 4. Efficiency of surfacing by various filler materials depending on welding current (downhand welding position)

chanical properties and high impact toughness (up to $-60{ }^{\circ} \mathrm{C}$ ).

Cost-saving potential in welding operations is limited to selection of efficient welding process, mechanization (increasing effective arcing time), downtime reduction (removing slag and spatter).

The greatest time-saving, compared to solid wire or electrode welding, is realized in out-ofposition welding (inconvenient conditions).

Flux-cored wires are applied with success in welding position butt joints (construction of large-diameter pipelines). For instance, «Northern Gateway» for natural gas supply to Germany was mainly made with such wires.

Application of pipelines for water or gas has a certain history:

- first pipeline systems for water supply (stone or wooden);

- 1911 - first attempt to weld a pipeline;

- 1922 - first application of arc welding of pipelines;

Table 1. Comparison of advantages of application of flux-cored and solid wires

\begin{tabular}{||l|c|c|}
\hline \multicolumn{1}{|c|}{ Criteria } & $\begin{array}{c}\text { Flux-cored } \\
\text { wire }\end{array}$ & Solid wire \\
\hline Total edge penetration & + & - \\
\hline Edge wetting; welding reliability & + & - \\
\hline Risk of lacks-of-penetration & + & - \\
\hline Smooth transitions without undercuts & + & - \\
\hline Cracking susceptibility & + & - \\
\hline Spattering & + & - \\
\hline Process stability & + & - \\
\hline Pore formation/internal defects & + & - \\
\hline Efficiency in cramped spaces & + & - \\
\hline Possibility of supplying special types & + & - \\
\hline Microalloying at low temperatures & + & - \\
\hline Price & + & - \\
\hline Production costs & - & + \\
\hline
\end{tabular}

Figure 3. Flux-cored wire classification 


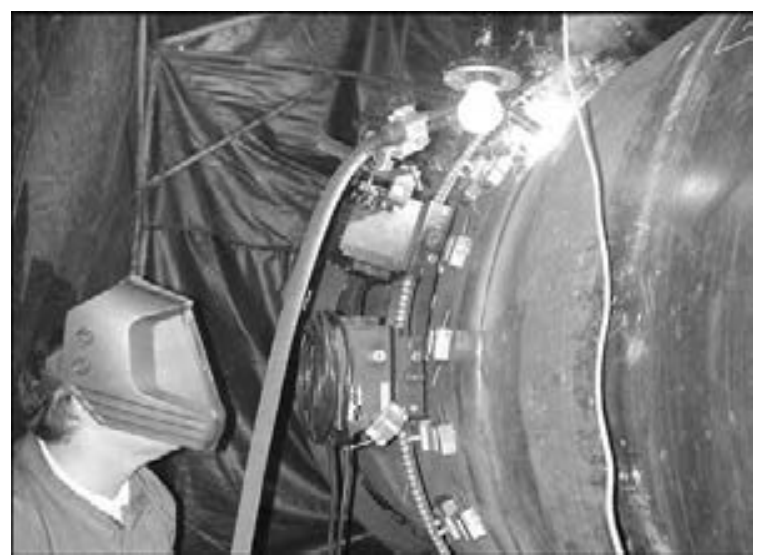

Figure 5. CRC Evans system for position butt welding (USA)

- 1927 - first attempt of welding using electrode with rutile type coating;

- 1969 - application of gas-shielded mechanized welding;

- 1980 - application of automatic analog welding systems;

- 1993 - application of technology of unsupported root welding;

- 2000 - application of automatic digital welding systems.

At present manual arc and automatic welding processes are used. Comparing them reveals the following advantages of automatic welding:

- better quality of welded joints in terms of ensuring required mechanical properties;

- saving on required numbers of staff (welders, operators) and equipment;

- faster operator training in automatic welding process;

- welding consumable saving;

- total saving in pipeline construction (downtime reduction).

About 25,000 km of various pipelines are built in the world every year. Considering that average pipe length is between 12 to $15 \mathrm{~m}$, more than $1.6 \mathrm{mln}$ pipes are required for the above pipeline length. Two variants of automatic welding are

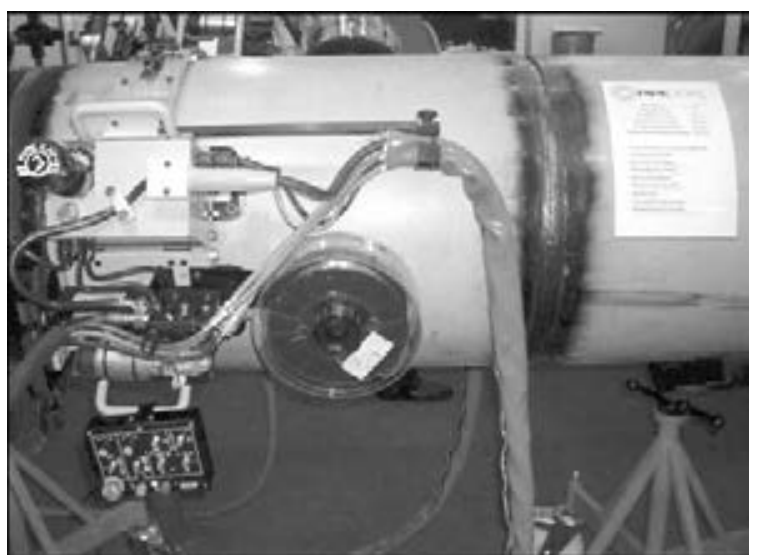

Figure 6. GULKO system for position butt welding (Canada)

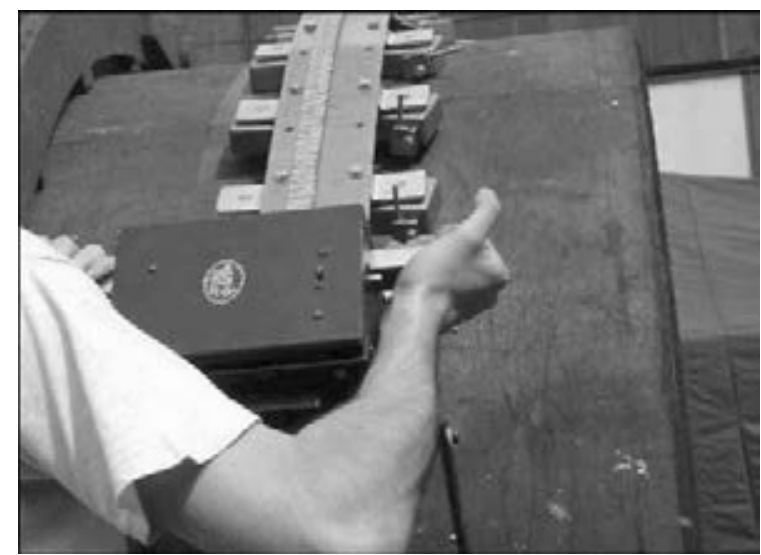

Figure 7. BUGO system for position butt welding (USA) mainly used: self-shielded flux-cored wire and gas-shielded flux-cored wire welding.

A range of flux-cored wires has been developed for gas-shielded welding of large-diameter pipes, allowing for the requirements on mechanical properties of applied pipe steels. Respective power sources and welding apparatuses were developed in parallel. Such a system includes the following components: two welding heads with a drive; power source and generator; flexible guide; controller and diverse spare parts.

Appropriate power source can be applied for the following welding processes: TIG; MMA with basic and rutile electrodes; $\mathrm{MIG} / \mathrm{MAG}$ with solid and flux-cored wire; welding with flux-cored wire for the root pass. Welding head operation is monitored using digital processing. Various welding programs are saved for welding, depending on pipe thickness and material. Welder selects a program, for instance, for root welding. Correction of welding parameters (within certain ranges during welding) can be performed from the control panel. General technological procedure is described below.

Weld root is welded first. This is done with solid welding wire of $1.14 \mathrm{~mm}$ diameter. Welding speed is $15-20 \mathrm{~cm} / \mathrm{min}$. Weld root height is $4 \mathrm{~mm}$. Beginning from the second layer, welding

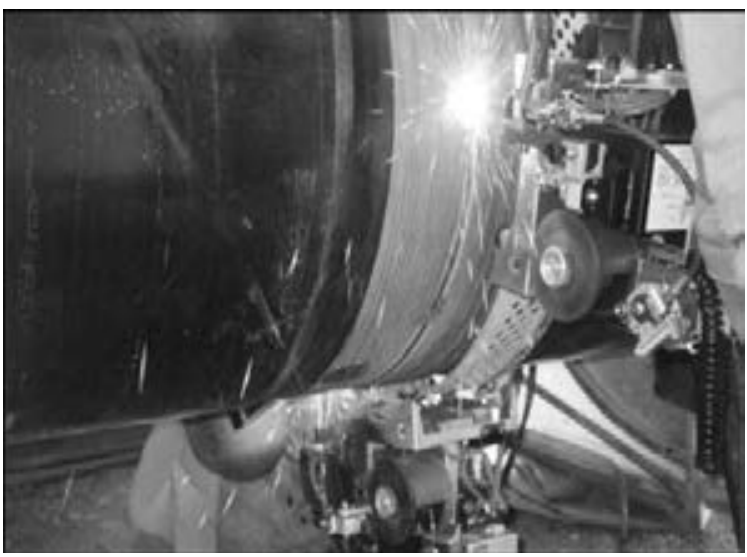

Figure 8. PWT system for position butt welding (Italy) 
VIII INTERNATIONAL CONFERENCE «WELDING CONSUMABLES»

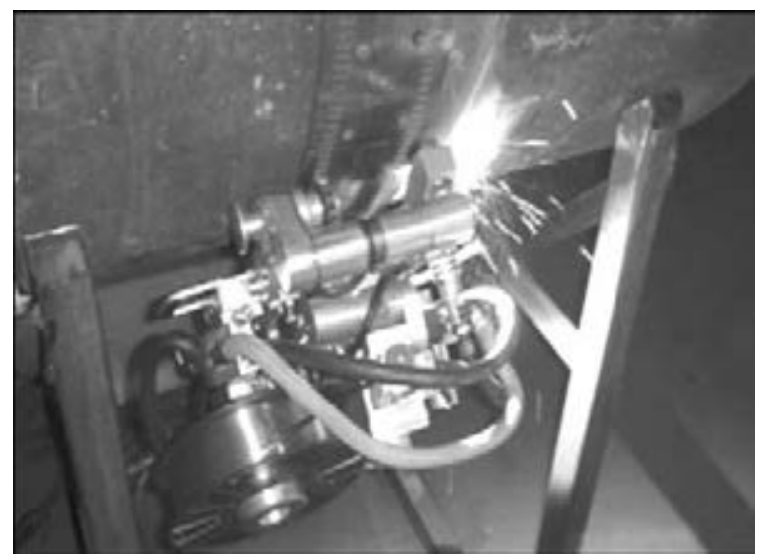

Figure 9. ITS system for position butt welding (Russia)

is performed with rutile flux-cored wire. Welding parameters mainly depend on the type of shielding gas, pipe diameter and wall thickness and edge preparation.

Two welding heads are usually used from both sides of the pipe. The second welding head starts welding only after the first welding head has operated for $3 \mathrm{~h}$. This ensures continuous twosided process for welding all the layers. Shielding gas selection should be given attention in welding. For most of the systems shielding gases of the following composition are used: $75-82 \% \mathrm{Ar}$, $25-18 \% \mathrm{CO}_{2}$.

Photos of pipe welding heads from different manufacturers are given in Figures 5-9. Systems differ by wire feed mechanisms, mechanism of heads fastening to the pipe, etc. Spools of 200$300 \mathrm{~mm}$ diameter of 5 to $16 \mathrm{~kg}$ weight are used. The operator should mainly follow the welding process, and some corrections can be made.

Metal-powder wires began to be used for root welding. This is related to the fact that solid wire of $560 \mathrm{MPa}$ grade has performed well at impact toughness testing up to $-20{ }^{\circ} \mathrm{C}$.

Impact toughness testing at $-40{ }^{\circ} \mathrm{C}$ and lower temperatures showed unreliable and unstable results that is due to insufficient alloying and absence of margin of viscoelastic properties of weld

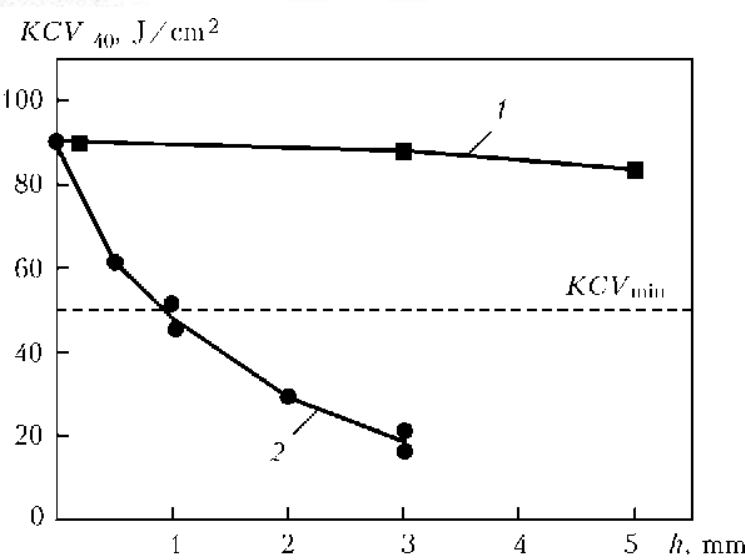

Figure 10. Dependence of impact toughness of lower-lying weld layers welded by solid (1) and flux-cored (2) wires on weld root layer height

metal in the root zone at critical low temperatures.

Geometrical features of the groove (gap and root face) determine the root weld height. When even $1 \mathrm{~mm}$ of the height of weld root layer, made with solid wire, is included into the section of the sample for $K C V$ impact toughness testing, an abrupt lowering of impact toughness values of the entire sample takes place. This leads to lowering of reliability of automatic welding process.

Figure 10 shows dependence of impact toughness of lower layers of the weld, made by MIG/MAG technology, on weld root layer height $\mathrm{h}$ in the impact testing sample*.

Analysis of Figure 10 leads to the conclusion that at not more than $3 \mathrm{~mm}$ height of weld root layer inside the groove and application of solid wire, weld metal impact toughness will always drop abruptly. To avoid it, it is necessary to mechanically saw out the extra height of weld root layer that is negative for the efficiency of automatic welding. When metal-powder wire is used, impact toughness of metal from weld lower layers is independent of root layer height. No mechanical removal of «extra» metal of the root layer is required here. Table 2 gives the recommended parameters for pipe welding. Figure 11

Table 2. Parameters of position welding of pipes by metal-powder wire

\begin{tabular}{||l|c|c|c|c|c|c|c||}
\hline \hline \multicolumn{1}{|c|}{ Weld layer } & $\begin{array}{c}\text { Welding } \\
\text { direction }\end{array}$ & $\begin{array}{c}\text { Wire feed rate, } \\
\mathrm{cm} / \mathrm{min}\end{array}$ & $\begin{array}{c}\text { Current kind, } \\
\text { polarity }\end{array}$ & Current, A & Arc voltage, V & $\begin{array}{c}\text { Wire extension, } \\
\mathrm{mm}\end{array}$ & $\begin{array}{c}\text { Welding speed, } \\
\mathrm{cm} / \mathrm{min}\end{array}$ \\
\hline Root & Downhill & $60-150$ & $=(+)$ & $90-130$ & $14-17$ & $5-16$ & $18-23$ \\
\hline Hot pass & Same & $620-660$ & Same & $230-250$ & $23-25$ & $7-12$ & $40-45$ \\
\hline Filling pass & Uphill & $530-600$ & » & $200-220$ & $22-23.5$ & $10-15$ & $30-35$ \\
\hline Facing pass & Same & $520-600$ & » & $190-220$ & $22-23.5$ & $10-15$ & $30-35$ \\
\hline
\end{tabular}

${ }^{*}$ Karasyov, M.B. (2012) New technologies, equipment and materials of CJSC «NPF ITC» In: Proc. of Int. Sci.-Technol. Seminar on Technologies of Resistance Arc and Specialized Welding Processes in Modern Industry (St.-Peterburg, May 16-18, 2012), 126-141. 
Table 3. Impact toughness of weld metal in joints made with rutile flux-cored wire

\begin{tabular}{|c|c|c|c|c|c|}
\hline Notch position & $\begin{array}{l}\text { Test temperature, } \\
{ }^{\circ} \mathrm{C}\end{array}$ & Sample section, mm & Fracture energy $K V, \mathrm{~J}$ & $\begin{array}{l}\text { Impact toughness } K C V \\
\mathrm{~J} / \mathrm{cm}^{2}\end{array}$ & $\begin{array}{c}\text { Averaged impact } \\
\text { toughness } K C V, \mathrm{~J} / \mathrm{cm}^{2}\end{array}$ \\
\hline \multirow{6}{*}{$\begin{array}{l}\text { Weld metal from be- } \\
\text { low }\end{array}$} & \multirow[t]{3}{*}{-40} & $8.04 \times 10$ & 85.8 & 106.7 & \multirow[t]{3}{*}{113.7} \\
\hline & & $8.06 \times 10.01$ & 88.2 & 109.3 & \\
\hline & & $8.06 \times 10.01$ & 100.8 & 124.9 & \\
\hline & \multirow[t]{3}{*}{-20} & $8.05 \times 10$ & 114.0 & 141.6 & \multirow[t]{3}{*}{139.3} \\
\hline & & $8.02 \times 10$ & 114.6 & 142.9 & \\
\hline & & $8.04 \times 10.01$ & 107.4 & 133.4 & \\
\hline \multirow{6}{*}{$\begin{array}{l}\text { Weld metal from } \\
\text { above }\end{array}$} & \multirow[t]{3}{*}{-40} & $8.05 \times 10.01$ & 88.8 & 110.2 & \multirow[t]{3}{*}{102.7} \\
\hline & & $8.03 \times 10$ & 91.8 & 114.3 & \\
\hline & & $8.04 \times 10.01$ & 67.2 & 83.5 & \\
\hline & \multirow[t]{3}{*}{-20} & $8.05 \times 10$ & 105.6 & 131.2 & \multirow[t]{3}{*}{138.1} \\
\hline & & $8.04 \times 10.02$ & 118.2 & 146.7 & \\
\hline & & $8.05 \times 10$ & 109.8 & 136.4 & \\
\hline
\end{tabular}

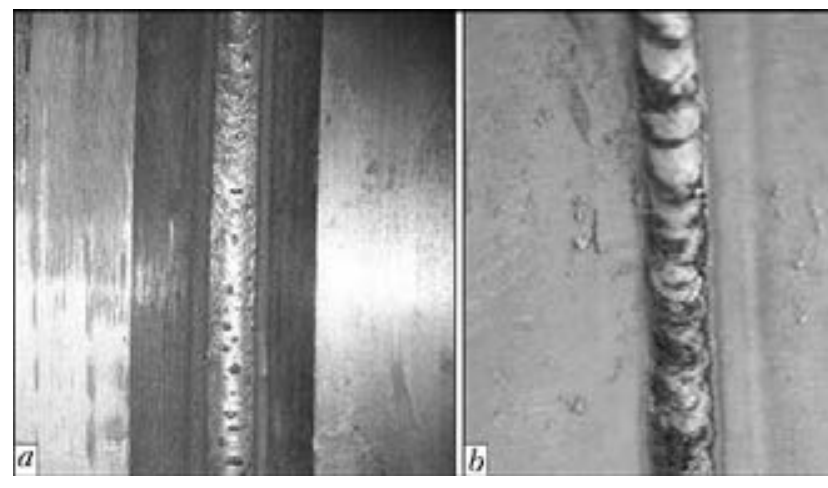

Figure 11. Appearance in welding with metal-powder wire of weld root $(a)$ and reverse side $(b)$

shows, as an example, appearance of weld root on a pipe produced by metal-powder wire welding.

Table 3 gives the values of impact toughness of welded metal produced by welding, here filling and facing layers were made with rutile fluxcored wire, and the root layer was made with solid wire. Figure 12 shows macrosection of such a joint.

Thus, the given data are indicative of the advantages of flux-cored wire application, com-

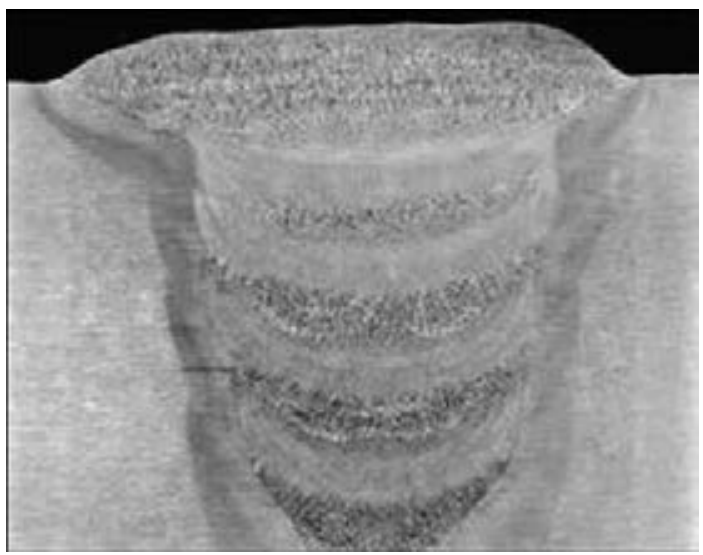

Figure 12. Macrosection $(\times 3.5)$ of welded joint made with rutile flux-cored wire

pared to solid wires and electrodes, in pipeline construction. Application of flux-cored wires provides high cost-effectiveness, compared to technology of electrode welding, and good mechanical indices.

Good prospects for flux-cored wire application are confirmed by examples given in this paper.

Received 30.04.2014 